\title{
New Triazolothiadiazine Derivative Inhibits \\ Stemness and Induces Cell Death in HCC by Oxidative Stress Dependent JNK Pathway Activation
}

Deniz Cansen Kahraman ( $\sim$ cansen@metu.edu.tr)

Middle East Technical University

Ebru Bilget Guven

Bilkent University

Peri S. Aytac

Hacettepe University

Gamze Aykut

Bilkent University

Birsen Tozkoparan

Hacettepe University

Rengul Cetin Atalay

University of Chicago

\section{Research Article}

Keywords: Nonsteroidal anti-inflammatory drug (NSAID), hepatocellular carcinoma (HCC), oxidative stress, JNK pathway, liver cancer stem cell (LCSC)

Posted Date: November 11th, 2021

DOI: https://doi.org/10.21203/rs.3.rs-1025268/v1

License: (c) (i) This work is licensed under a Creative Commons Attribution 4.0 International License.

Read Full License 


\section{Abstract}

Hepatocellular carcinoma (HCC) is a highly heterogeneous cancer, and resistant to both conventional and targeted chemotherapy. (NSAIDs) Recently, nonsteroidal anti-inflammatory drugs (NSAIDs) have been shown to decrease the incidence and mortality of different types of cancers. Here, we investigated the cellular bioactivities of a series of triazolothiadiazine derivatives on HCC, which have been previously reported as potent analgesic/anti-inflammatory compounds. From the initially tested 32 triazolothiadiazine NSAID derivatives, 3 compounds were selected based on their $\mathrm{IC}_{50}$ values for further molecular assays on 9 different HCC cell lines. 7b, which was the most potent compound, induced G2/M phase cell cycle arrest and apoptosis in HCC cells. Cell death was due to oxidative stress-induced JNK protein activation, which involved the dynamic involvement of ASK1, MKK7, and c-Jun proteins. Moreover, $7 \mathrm{~b}$ treated nude mice had a significantly decreased tumor volume and prolonged disease-free survival. $7 \mathrm{~b}$ also inhibited the migration of HCC cells and enrichment of liver cancer stem cells (LCSCs) alone or in combination with sorafenib. With its ability to act on both proliferation, stemness and the migration of HCC cells, 7b can be considered for the therapeutics of HCC, which has an increased rate of incidence $\sim 3 \%$ annually.

\section{Introduction}

Hepatocellular carcinoma (HCC) is one of the most common cancer types and second in terms of cancerrelated mortality worldwide [1]. HCC which has a very heterogeneous structure and develops over many years as a multi-step process [2]. Patients with advanced stage HCC have very limited and mostly palliative treatment options due to the chemo-resistant nature of the disease [3,4]. Hepatic injury initiated by any of the etiologies such as chronic hepatitis, alcohol abuse or aflatoxin-B1-intoxication, and recently obesity, results in continuous destructive-regenerative cycles and causes cirrhosis, which further induces carcinogenesis leading to HCC [5]. Recently, Sorafenib, lenvatinib, regorafenib, atezolizumab plus bevacizumab, cabozantinib and ramucirumab are the drugs approved by FDA for the systemic therapy of HCC [6]. Although sorafenib and Lenvatinib are regarded as the best treatment options for advanced HCC patients, capable of inducing apoptosis and inhibiting angiogenesis and proliferation of tumor cells, they can extend patient survival for about 3 months $[7,8]$. Combinatorial approaches involving the use of chemotherapeutic agents together with Sorafenib in HCC have been reported to show limited usage due to the high toxicity and unconvincing efficacy in prolonging survival of HCC patients $[9,10]$. In addition, recent studies report that acquired drug resistance to sorafenib is very common. Multiple factors and mechanisms are identified to be involved in the development of sorafenib resistance followed by progression of the disease. Tumor microenvironment, EGFR activation, compensatory pathways such as PI3K/AKT and JAK/STAT and the presence of cancer stem cells (CSCs) are only some of these mechanisms [11]. Therefore, it is essential to discover reliable drug candidates that could provide novel therapeutic options for advanced HCC patients.

Nonsteroidal anti-inflammatory drugs (NSAIDs) have been used for the treatment of acute and chronic conditions with pain and inflammation for many years. Recently, clinical studies have emphasized the 
role of NSAIDs in cancer treatment, such that NSAIDs are effective in decreasing the incidence and mortality of many cancer types [12-15]. 1,2,4-Triazole is an important scaffold in the field of medicinal chemistry. Currently, a group of compounds carrying the 1,2,4-triazole ring, named anastrozole (1), letrozole (2) vorozole (3), are explicitly used in the treatment of estrogen receptor-positive breast cancer as nonsteroidal aromatase inhibitors (Fig. 1) [16,17]. For this reason, the five-membered 1,2,4-triazole ring system is a suitable heterocyclic core structure for the design of new anticancer compounds. During the last two decades, it has been determined that triazolopyridazine, triazolotriazine, triazolothiadiazine, and triazolothiadiazole derivatives (condensed 1,2,4-triazole derivatives) have cytotoxic activities in many cancer cells by inducing various molecular mechanisms [18-25].

Since more than $90 \%$ of the liver cases are associated with chronic inflammation [26], NSAIDs could be effective against HCC. Indeed, in one of our previous studies, the anticancer effects of triazolothiadiazines on epithelial cancers, especially liver cancer, were demonstrated, where compounds were able to induce apoptotic cell death due to oxidative stress, acting on Akt protein [13]. Furthermore recently the antiproliferative bioactivities of a compound with triazolothiadiazine scaffold against human hepatoma cell line (HepG2) was reported [27]. In light of this information and as a part of our ongoing interest on liver cancer therapeutics [28], we investigated the anticancer effects of our newly synthesized compounds bearing triazolethiones (1-8) or triazolothiadiazine (1a-8c) cores, which we reported as potent analgesic/anti-inflammatory compounds previously (Fig. 2) [24,25].

This study not only evaluates the in vitro and in vivo antitumor activity of the compounds against liver cancer, but also to characterizes the form of cell death induced by the compounds and identifies the underlying molecular mechanism of action with the most potent compound.

\section{Materials And Methods}

\section{Synthesis NSAID Triazolothiadiazine derivatives}

Synthesis of 4-amino-3-substituted-1,2,4-triazole-5-thiones (Compounds 1-8), was carried out by melting some aralkyl carboxylic acid derivatives with thiocarbohydrazide according to the procedure described previously [25,29]. Synthesis of 3,6-disubstituted-7H+1,2,4-triazolo[3,4-b]-1,3,4-thiadiazines (1a-8c) was carried out by reacting relevant 4-amino-3-substituted-1,2,4-triazole-5-thiones (1-8) with appropriate phenacyl halides in anhydrous ethanol under reflux, 3,6-disubstituted-7H1,2,4-triazolo[3,4-b]-1,3,4thiadiazines (1a-8c) $[25,29]$. Physical properties and spectral data characterizing the structure of the synthesized compounds were reported previously [24,25].

\section{Drugs and Chemicals}

JNK inhibitor (cat. \# 420119) was provided from Calbiochem, Sorafenib (cat. \# S7397), and DAPT (cat. \# S2215) was provided from Selleck chemicals, Taxol was provided from (Bristol Myers Squibb). Camptothecin was purchased from Sigma (cat. \# C9911).

\section{Cell culture}


Nine hepatocellular carcinoma cell lines, and one colon carcinoma cell line were obtained from the following sources: Huh7 (JCRB0403), HepG2 (ATCC HB-8065), Hep3B (ATCC HB-8064), PLC (ATCC CRL8024), SK-Hep1 (ATCC HTB52) Mahlavu [30], FOCUS [31], SNU182 (ATCC CRL-2235), SNU387 (ATCC CRL2237), SNU475 (ATCC CRL-2236) and, HCT116 (ATCC CCL-247). Cells were grown in DMEM, (Dulbecco's Modified Eagle Medium) or RPMI (Roswell Park Memorial Institute)-1640 growth medium supplemented with $10 \%$ fetal bovine serum (FBS), $1 \%$ non-essential amino acids, $1 \%$ L-glutamine, $1 \%$ penicillin and streptomycin (GIBCO, Invitrogen) at $37^{\circ} \mathrm{C}$ under $5 \% \mathrm{CO}_{2}$. All cell lines used in this study are STR (short tandem repeat) authenticated. Cells are regularly tested for mycoplasma contamination using mycoplasma detection kit (MycoAlert ${ }^{\text {TM }}$, Lonza). The passaging of the cells did not exceed 8-10 passages (2 times a week) throughout the experiments.

\section{Sulforhodamine B (SRB) assay}

Cells were inoculated (1000-5000cell) for $24 \mathrm{~h}$ and treated with the increasing concentrations of compounds $(40-0.01 \mu \mathrm{M})$ for $72 \mathrm{~h}$. Cells were washed, and plates were stained with SRB (Sigma Aldrich) as described previously [32]. The absorbance values were obtained at $515 \mathrm{~nm}$ using a plate reader (ELx800, BioTek).

\section{Real-time cell growth analysis (RT-CES)}

Cells were plated on to E-96 plates cells (1000-5000 cells/well). Cells were treated with the compounds, and cell index $(\mathrm{Cl})$ values were recorded (RT-CES, xCELLigence, ACEA Biosciences) and analyzed as described previously [33]. Cell growth curves were generated using the time-zero normalized $\mathrm{Cl}$ values.

\section{Cell cycle analysis by flow cytometer}

HCC cells were inoculated in $100 \mathrm{~mm}$ culture dishes. After $24 \mathrm{~h}$, cells were treated with compound $7 \mathrm{~b}$ and its DMSO control. 24h later, cell pellets were collected and re-suspended in $1 \mathrm{ml}$, ice-cold 1xPBS, and fixed by adding $2.5 \mathrm{~mL}, 70 \%$ ice-cold ethanol. Next, the cell pellets were re-suspended in Propidium iodide (PI) solution $(50 \mu \mathrm{g} / \mathrm{mL}$ PI (Sigma Aldrich), $0.1 \mu \mathrm{g} / \mathrm{mL}$ RNaseA (Fermentas), 0.05\% Triton-X-100, 1xPBS) and incubated for at $37^{\circ} \mathrm{C}$ for 40 minutes at dark. Cell cycle analysis was performed using FACSCalibur (BD Biosciences) and CellQuest Software (Becton Dickinson).

\section{Detection of ER-stress}

Total RNA was isolated from cells via the Nucleospin RNA II kit (Macherey-Nagel) according to the manufacturer's protocol. First strand cDNA synthesis was performed using RevertAid First Strand cDNA synthesis kit (Thermo Scientific). Semi-quantitative reverse transcriptase PCR (RT-PCR) assay was performed using XBP1 specific primers. The primer sequences; GAPDH forward primer: GGCTGAGAACGGGAAGCTTGTCAT, GAPDH reverse primer: CAGCCTTCTCCATGGTGGTGAAGA, XBP1 forward primer: TTACGAGAGAAAACTCATGGCC, XBP1 reverse primer: GGGTCCAAGTTGTCCAGAATGC.

\section{Reactive Oxygen Species (ROS) detection}


Huh7 and Mahlavu cells were seeded into $10 \mathrm{~cm}$ culture dish (100,000-300,000 cells/dish). Next day, cells were treated with compound 7b, DMSO or Selenium (Se) deficient serum-free media for 8,12 or $24 \mathrm{~h}$. Flow cytometric analysis of cells for ROS induction at $12 \mathrm{~h}$ was done with the Oxidative Stress kit (MCH100111, Merck Millipore) using MUSE ${ }^{\mathrm{TM}}$ Cell Analyzer. In parallel, cells were also visualized under a fluorescence microscope (Nikon Eclipse Ti-E), which were incubated with ROS assay solution (10 mM HEPES buffer, $10 \mathrm{mM}$ glucose, $1 \mu \mathrm{M}$ DCFH-DA (Dichloro-dihydro-fluorescein diacetate) in $1 \times \mathrm{PBS}$ ). Se-deficient serumfree medium was used as the positive control [34].

\section{Western Blot analysis}

$\mathrm{HCC}$ cells were treated with increasing concentrations of compound $7 \mathrm{~b}\left(+: \mathrm{IC}_{50},++: 2 \times \mathrm{IC}_{50}\right)$ or with DMSO control. After 24h, cells were harvested by scraping, washed with PBS, lysed with RIPA lysis buffer on ice and centrifuged at $13000 \mathrm{rpm}$ for $20 \mathrm{~min}$. The supernatants were collected, and the protein concentration was measured using Bradford assay. For SDS-PAGE, 20-50 $\mu \mathrm{g}$ of protein was prepared, and samples were run using the Novex ${ }^{\circledR}$ NuPAGE $®$ Bis-Tris Electrophoresis system according to the manufacturer's protocol. Transfer of proteins to nitrocellulose membrane was done via XCell IITM Blot Module. The blots were incubated with primary antibodies against PARP-1 (Santa Cruz Biotechnology Cat\# sc-8007, 1:1,000 dilution), SAPK/JNK (Cell Signaling Technology Cat\# 9252, 1:300 dilution), Phospho-SAPK/JNK (Thr183/Tyr185) (Cell Signaling Technology Cat\# 9251, 1:200 dilution), phosphop38 (Thr180/Tyr182) (Cell Signaling Technology Cat\# 9211S, 1:500 dilution), phospho-c-Jun (Santa Cruz Biotechnology Cat\# sc-822, 1:200 dilution), phospho-ASK1 (Thr845) (Cell Signaling Technology Cat\# 3765, 1:500 dilution), phospho-ASK1 (Ser966) (Genscript, Cat\# A00340, 1:500 dilution), phospho-ASK1 (Ser83) (Abcam Cat\# ab47304, 1:500 dilution), phospho-MKK7 (Ser271/Thr275) (Cell Signaling Technology Cat\# 4171, 1:500 dilution), phospho-MKK4 (S257 + T261) (Abcam Cat\# ab4760, 1:300 dilution), calnexin (Sigma-Aldrich Cat\# C4731, 1:5000 dilution), and actin (Santa Cruz Biotechnology Cat\# sc-1616, 1:5000 dilution) in $0.1 \%$ TBST at $4^{\circ} \mathrm{C}$ overnight, followed by secondary antibody incubations with HRP-conjugated goat anti-mouse IgG (Sigma-Aldrich Cat\# A0168, 1:5000 dilution), rabbit anti-goat IgG (Sigma-Aldrich Cat\# A8919, 1:5000 dilution), or goat anti-rabbit IgG (Sigma-Aldrich Cat\# A6154, 1:5000 dilution) for $1 \mathrm{~h}$ at room temperature. Proteins were visualized by using the enhanced chemiluminescence (ECL) system.

\section{In vivo mouse xenograft experiments}

All animals received human care, and study protocols comply with the institution's guidelines. Animal ethics committee of Bilkent University approved the study protocol. In addition, all studies were reported in accordance with the ARRIVE (Animal Research: Reporting of In Vivo Experiments) guidelines. Mahlavu cells prepared in DMEM $(10,000,000$ cells/mouse) were injected subcutaneously (SC) to the flank of 8-16 weeks old male nude mice as described previously [35]. Drug treatment was initiated once the tumor volume reached $150 \mathrm{~mm}^{3}$. The subjects received compound $7 \mathrm{~b}(100 \mathrm{mg} / \mathrm{kg})$ in simple syrup $(16 \mathrm{~g}$ glucose in $9 \mathrm{~g} \mathrm{ddH}_{2} \mathrm{O}$ ) by oral gavage, and the control group mice received $100 \mu$ simple syrup only twice a week for 21 days. Nude mice were not treated for the following 3 weeks and imaged with Magnetic Resonance Imaging (acquired with 3-TESLA Siemens MAGNETOM Trio, UMRAM Center, Bilkent 
University) following intraperitoneal (ip) injection of anesthesia regimen consisting of $10 \mathrm{mg} / \mathrm{kg}$ xylaxin and $90 \mathrm{mg} / \mathrm{kg}$ ketamine.

\section{Detection of liver cancer stem cell (LCSC) enrichment by flow cytometry}

Huh7 and Mahlavu cells were seeded onto 100mm culture dishes. The next day cells were treated with compound 7b, sorafenib, DAPT, or DMSO control at their $\mathrm{IC}_{50}$ concentrations and with different combinations of sorafenib and compound 7b. Fluorescence labeling of LCSCs was done using primary antibodies against CD133 (Miltenyi Biotec Cat\# 130-090-664), and anti-biotin-PE (Miltenyi Biotec Cat\# 130-090-756), EpCAM (Miltenyi Biotec Cat\# 130-080-301), or CD90 (Miltenyi Biotec Cat\# 130-095-403) for flow cytometry analysis as described previously [36]. Mouse-lgG-FITC (Miltenyi Biotec Cat\# 130-092-213), and mouse-lgG-biotin antibodies (Miltenyi Biotec Cat\# 130-093-018) were used as isotype controls. DAPT (Notch pathway inhibitor) was used as a positive control for cancer stem cell inhibition. Results for each treatment group were compared to that of DMSO control. Changes in the positivity of CD133+/EpCAM+ cells or CD90+ cells were indicative of enrichment or reduction of the LCSC population. BD Accuri C6 and Novoctye flow cytometer (ACEA Biosciences) were used for flow cytometric analysis.

\section{Sphere formation assay}

Sphere formation was triggered as described previously [37] in ultra-low attachment 96-well plates. Images of spheres and measurements of sphere size and number were assessed using light microscopy (Zeiss) after 6-12 days of incubation.

\section{Cell migration assay}

To test the effect of compound 7b on the migration capacity of Huh7 and Mahlavu cells, RT-CES DP system was used. The lower chamber of the 16 well CIM-plate was filled with $160 \mu$ of $10 \%$ FBS containing complete DMEM, and the upper chamber was placed on top of the lower chamber. After 1 hour at $37^{\circ} \mathrm{C}$, cells that were prepared in the presence of different concentrations of compound $7 \mathrm{~b}(2 \mu \mathrm{M}$ for Huh7 and $8 \mu \mathrm{M}$ for Mahlavu), Taxol (20ng/ml) or DMSO inside serum-free DMEM, to be seeded into the upper chamber (30000-50000 cell/well). CIM-plates were placed into the system after 30 min of incubation at room temperature (RT), and Cl values were obtained every 15 min for 24 hours. Time-zero normalized $\mathrm{Cl}$ values were used to generate time-dependent migration curves for each experimental group.

\section{Statistical analysis}

Data were obtained from three independent experiments, and all experiments were carried out with $n \geq 3$ biological replicates. Statistical analysis for in vitro data was done using a Student's t-test. All in vivo experimental data were analyzed using ANOVA, $n=5-6$ mice/group (Graphpad Prism version 7.0, or Microsoft Excel). * $p<0.05, * \star p<0.01,{ }^{* \star *} p<0.001$. 


\section{Cytotoxic bioactivities of 4-amino-3-substituted-1,2,4- triazole-5-thiones (1-8) and 3,6-disubstituted-7H-1,2,4- triazolo[3,4-b]-1,3,4-thiadiazines (1a-8c) on cancer cells}

Cytotoxic bioactivities of 8 compounds with 4-amino-3-substituted-1,2,4-triazole-5-thiones (1-8) and 24 compounds with 3,6-disubstituted-7H-1,2,4-triazolo[3,4-b]-1,3,4-thiadiazines (1a-8c) were tested on primary liver and colon cancer cell lines by SRB (Table 1). While 4-amino-3-substituted-1,2,4-triazole-5thiones (1-8) did not exhibit cytotoxic activities on two epithelial cancer cell lines (Huh7 and HCT116), compounds with triazolothiadiazine core had significant cytotoxicity, comparable to the effect of a wellknown chemotherapeutic drug Camptothecin (CPT). Among all the compounds, three of them $(7 \mathrm{a}, 7 \mathrm{~b}$, and 7c) had prominent cytotoxic activities at concentrations ranging from 0.3-5.3 $\mu \mathrm{M}$ (Table 1). These compounds were then screened against a panel of HCC cell lines (Huh7, HepG2, Hep3B, PLC, SK-Hep1, Mahlavu, FOCUS, SNU182, and SNU475). $\mathrm{IC}_{50}$ values were $\sim 7-23 \mu \mathrm{M}$ for $7 \mathrm{a}, \sim 0.2-1 \mu \mathrm{M}$ for $7 \mathrm{~b} \sim 12-50 \mu \mathrm{M}$ for 7c (Supplementary Table S1). With cytotoxic doses smaller than $5 \mu \mathrm{M}$, compound $7 \mathrm{~b}$ was identified as a potent anticancer agent against liver cancer cells. Interestingly, this compound was previously reported to have the most promising and reliable anti-inflammatory activity among newly synthesized 3,6disubstituted 7H-1,2,4-triazolo[3,4-b]-1,3,4-thiadiazine derivatives [25,29]. Next, we evaluated the anticancer activities of compound $7 \mathrm{~b}$ against a panel of HCC cell lines consisting of Huh7, HepG2, Mahlavu, FOCUS, SNU475, and SNU387 to determine the time- and dose-cell growth inhibitory effect. Time-dependent $\mathrm{IC}_{50}$ values of compound $7 \mathrm{~b}$ for each $\mathrm{HCC}$ cells were calculated accordingly. (Table 2). 
Table 1

$\mathrm{IC}_{50}$ values of 4-amino-3-substituted-1,2,4-triazole-5-thiones (1-8) and 3,6-disubstituted 1,2,4-triazolo[3,4-b]-1,3,4thiadiazines (1a-8c) determined by SRB assay.

\begin{tabular}{|c|c|c|c|c|c|}
\hline Compound & $\mathbf{R}$ & $R_{1}$ & $\mathrm{n}$ & Huh7 & HCT116 \\
\hline 1 & $2-\mathrm{OCH}_{3}$ & - & 1 & $\mathrm{NI}$ & $\mathrm{NI}$ \\
\hline $1 a$ & $2-\mathrm{OCH}_{3}$ & $\mathrm{H}$ & 1 & 37.6 & $>40$ \\
\hline $1 b$ & $2-\mathrm{OCH}_{3}$ & $\mathrm{Cl}$ & 1 & $\mathrm{NI}$ & $\mathrm{NI}$ \\
\hline $1 c$ & $2-\mathrm{OCH}_{3}$ & $\mathrm{~F}$ & 1 & $>40$ & $\mathrm{NI}$ \\
\hline 2 & $2-\mathrm{OCH}_{3}$ & - & 2 & $\mathrm{NI}$ & $\mathrm{NI}$ \\
\hline $2 a$ & $2-\mathrm{OCH}_{3}$ & $\mathrm{H}$ & 2 & $\mathrm{NI}$ & $\mathrm{NI}$ \\
\hline $2 b$ & $2-\mathrm{OCH}_{3}$ & $\mathrm{Cl}$ & 2 & 23 & $\mathrm{NI}$ \\
\hline $2 c$ & $2-\mathrm{OCH}_{3}$ & $\mathrm{~F}$ & 2 & $>40$ & $\mathrm{NI}$ \\
\hline 3 & 3- $\mathrm{OCH}_{3}$ & - & 1 & $\mathrm{NI}$ & $>40$ \\
\hline $3 a$ & $3-\mathrm{OCH}_{3}$ & $\mathrm{H}$ & 1 & 24.7 & 30.9 \\
\hline $3 b$ & $3-\mathrm{OCH}_{3}$ & $\mathrm{Cl}$ & 1 & $>40$ & $\mathrm{NI}$ \\
\hline $3 c$ & $3-\mathrm{OCH}_{3}$ & $\mathrm{~F}$ & 1 & $>40$ & $\mathrm{NI}$ \\
\hline 4 & 3- $\mathrm{OCH}_{3}$ & - & 2 & $\mathrm{NI}$ & $\mathrm{NI}$ \\
\hline $4 a$ & $3-\mathrm{OCH}_{3}$ & $\mathrm{H}$ & 2 & $>40$ & $\mathrm{NI}$ \\
\hline $4 b$ & $3-\mathrm{OCH}_{3}$ & $\mathrm{Cl}$ & 2 & $>40$ & $\mathrm{NI}$ \\
\hline $4 c$ & $3-\mathrm{OCH}_{3}$ & $\mathrm{~F}$ & 2 & $\mathrm{NI}$ & $\mathrm{NI}$ \\
\hline 5 & 4- $\mathrm{OCH}_{3}$ & - & 1 & $\mathrm{NI}$ & $>40$ \\
\hline $5 a$ & $4-\mathrm{OCH}_{3}$ & $\mathrm{H}$ & 1 & $>40$ & $>40$ \\
\hline $5 b$ & $4-\mathrm{OCH}_{3}$ & $\mathrm{Cl}$ & 1 & $>40$ & $\mathrm{NI}$ \\
\hline $5 c$ & $4-\mathrm{OCH}_{3}$ & $\mathrm{~F}$ & 1 & 28.6 & $\mathrm{NI}$ \\
\hline 6 & 4- $\mathrm{OCH}_{3}$ & - & 2 & $\mathrm{NI}$ & $>40$ \\
\hline
\end{tabular}

* Nl: no inhibition 


\begin{tabular}{|c|c|c|c|c|c|}
\hline Compound & $\mathbf{R}$ & $\mathrm{R}_{1}$ & $\mathbf{n}$ & Huh7 & HCT116 \\
\hline $6 a$ & $4-\mathrm{OCH}_{3}$ & $\mathrm{H}$ & 2 & 18.8 & 35.4 \\
\hline $6 \mathrm{~b}$ & $4-\mathrm{OCH}_{3}$ & $\mathrm{Cl}$ & 2 & 30.1 & $>40$ \\
\hline $6 c$ & $4-\mathrm{OCH}_{3}$ & $\mathrm{~F}$ & 2 & $\mathrm{NI}$ & $\mathrm{NI}$ \\
\hline 7 & $3,4,5-\mathrm{OCH}_{3}$ & - & 1 & $\mathrm{NI}$ & $\mathrm{NI}$ \\
\hline $7 a$ & $3,4,5-\mathrm{OCH}_{3}$ & $\mathrm{H}$ & 1 & 5 & 15 \\
\hline $7 b$ & $3,4,5-\mathrm{OCH}_{3}$ & $\mathrm{Cl}$ & 1 & 0.3 & NA \\
\hline $7 c$ & $3,4,5-\mathrm{OCH}_{3}$ & $\mathrm{~F}$ & 1 & 5.3 & 17.2 \\
\hline 8 & $3,4,5-\mathrm{OCH}_{3}$ & - & 2 & $\mathrm{NI}$ & $\mathrm{NI}$ \\
\hline $8 a$ & $3,4,5-\mathrm{OCH}_{3}$ & $\mathrm{H}$ & 2 & 27.8 & $\mathrm{NI}$ \\
\hline $8 b$ & $3,4,5-\mathrm{OCH}_{3}$ & $\mathrm{Cl}$ & 2 & 13.7 & $>40$ \\
\hline $8 c$ & $3,4,5-\mathrm{OCH}_{3}$ & $\mathrm{~F}$ & 2 & 40 & $\mathrm{NI}$ \\
\hline СРТ & & & & $<0.1$ & $<0.1$ \\
\hline \multicolumn{6}{|c|}{ * NI: no inhibition } \\
\hline
\end{tabular}

Table 2

$\mathrm{IC}_{50}$ values of compound $7 \mathrm{~b}$ in $\mu \mathrm{M}$ concentrations against Huh7, HepG2, Mahlavu, FOCUS, SNU475 and SNU387 cells at 24,48 and 72 hours determined by SRB assay.

\begin{tabular}{|llll|}
\hline & 24h & 48h & 72h \\
\hline Huh7 & $0.7 \pm 0.20$ & $0.2 \pm 0.10$ & $0.2 \pm 0.01$ \\
\hline HepG2 & $1.9 \pm 0.80$ & $1.1 \pm 0.20$ & $1.3 \pm 0.30$ \\
\hline Mahlavu & $1.3 \pm 0.30$ & $1.2 \pm 0.10$ & $1.3 \pm 0.20$ \\
\hline FOCUS & $0.8 \pm 0.10$ & $0.5 \pm 0.10$ & $0.4 \pm 0.01$ \\
\hline SNU475 & $2.1 \pm 0.20$ & $1.6 \pm 0.20$ & $1.7 \pm 0.20$ \\
\hline SNU387 & $4.7 \pm 1.00$ & $1.3 \pm 0.20$ & $2.5 \pm 0.40$ \\
\hline
\end{tabular}


A label-free real-time cell monitoring system (RT-CES) capable of measuring cell growth by electrical impedance detection was used to determine the real-time anticancer activity of compound $7 \mathrm{~b}$. It was demonstrated that compound $\mathbf{7 b}$ inhibits cell growth in a dose- and cell line-dependent manner, similar to our initial results with the SRB assay (Fig. 3a). Further experiments were performed to decipher the mechanism underlying this activity. In the presence of compound $7 \mathrm{~b}$, cleaved Poly-ADP-ribosylpolymerase (PARP) fragments that are indicative of activated apoptotic pathway, were visible in most of the HCC cells after $24 \mathrm{~h}$ (Fig. 3b). To further enlighten the mechanism beneath the apoptotic cell death in these cells, cell cycle distribution in the presence of compound $7 \mathrm{~b}$ was examined by flow cytometry analysis of propidium iodide-stained cells. Compound $7 \mathrm{~b}$ induced dose dependent G2/M arrest in HCC cell lines after $24 \mathrm{~h}$ (Fig. 3c).

\section{Cell cycle arrest and apoptosis induced by compound 7b is associated with ROS accumulation}

The most common underlying mechanisms inducing G2/M arrest followed by apoptosis in cells are ERstress and the accumulation of reactive oxygen species (ROS) [38,39]. Since, XBP-1 splicing via semiquantitative PCR is an indicative of ER-stress induction [40], we evaluated the levels of spliced XBP-1 in Huh7 cells upon treatment with compound 7b, DMSO or 500 $\mathrm{ng} / \mathrm{mL}$ tunicamycin (TN) for 24 hours. Tunicamycin was used as a positive control at ER stress-inducing dose [41]. Compound $7 \mathrm{~b}$ did not induce ER-stress-specific XBP-1 splicing in these cells, unlike TN (Supplementary Figure S2). Then, we tested whether oxidative stress upon ROS accumulation was triggered by compound $7 \mathrm{~b}$ in Huh7 and Mahlavu cells, which were treated with increasing concentrations of compound $7 \mathrm{~b}(1.5$ and $3 \mu \mathrm{M})$ for 8,12 , and 24 hours. In the presence of compound $7 b$, the accumulation of ROS was detected significantly in both Huh7 and Mahlavu cells by DCFH-DA staining, which was in parallel quantified and statistically analyzed by flow cytometric analysis (Fig. 4a and 4b).

\section{Activation of JNK pathway upon treatment with compound $7 \mathrm{~b}$}

It is well described in literature that activation of c-Jun NH2-terminal kinases (JNKs), also known as stress-activated protein kinases (SAPKs), is a typical response to many forms of stress and are vital for the induction of G2/M arrest and apoptosis [42,43]. Therefore, we checked the levels of activated JNK and its downstream element c-Jun, which is a transcription factor phosphorylated by JNK1 and JNK2, in HCC cells treated with 7b, or JNKInhV relative to DMSO treated cells for $24 \mathrm{~h}$. We observed a significant increase in the phosphorylated-JNK and phosphorylated-c-Jun protein levels upon compound $7 \mathbf{b}$ treatment (Fig. 5a). We tested the effect of $7 b$ on the regulation of $p 38$, which is another ROS-mediator activated protein [44], and found that phospho-p38 levels also increase significantly upon $7 \mathrm{~b}$ treatment in HCC cell lines (Fig. 5a). To further investigate the effects of ROS accumulation on the upstream components of the JNK signaling pathway, levels of upstream elements activating JNK such as MKK-4, MKK7 [45] and apoptosis signal-regulating kinase 1 (ASK1) proteins $[46,47]$ were analyzed. We found that 
compound 7b increased the phospho-MKK7 protein levels (Fig. 5b) but did not change phospho-MKK4 levels in HCC cells (Supplementary Figure S3). Furthermore, 7b also altered the phosphorylation status of its upstream activator ASK1 (Fig. 5b). Altogether the signaling cascade induced by compound $7 \mathrm{~b}$ that lead to the apoptosis of HCC cells is summarized in Fig. $5 \mathrm{c}$.

\section{in vivo anti-tumor activity of compound $7 \mathrm{~b}$ in mouse xenografts}

Mahlavu cell xenografts in nude mice were used to determine the in vivo antitumor effect of compound 7b. Mahlavu cells was selected due to its significant response to compound $\mathbf{7 b}$ as well as its poorly differentiated and highly metastatic nature [48]. We observed that compound $7 \mathrm{~b}$ increased the overall survival of nude mice (Fig. 6a). Moreover, the tumor volumes were significantly decreased in the compound $7 \mathrm{~b}$ treated group as demonstrated by the representative MRI images (Fig. 6b). Altogether, our in vivo data revealed that compound $\mathbf{7 b}$ is orally tolerable in nude mice and is a novel and potentially effective drug candidate against HCC.

\section{Effect of compound 7b on liver cancer stem cell enrichment}

Tumor initiating cells of liver, so called (liver cancer stem cells-LCSCs), are known to be capable of reconstituting the tumor by themselves, trigger metastatic events, and enhance drug resistance in cancer cells [49]. Therefore, we tested compound $7 \mathrm{~b}$ for its effect on enrichment LCSCs, which can be quantified by the detection of CSC markers found on the surface of these cells. For this purpose, Huh7 and Mahlavu cells were treated with compound $\mathbf{7 b}$ and other inhibitors such as Sorafenib, DAPT or DMSO control at $\mathrm{IC}_{50}$ concentrations for 72 hours. Cells that remained viable after treatment were collected, and the expression of LCSC markers CD133 and EpCAM (for Huh7) and CD90 (for Mahlavu) were evaluated by flow cytometry. Results have revealed that compound $7 \mathrm{~b}$ was able to decrease the CD133+/EpCAM+ population in Huh7 cells and CD90+ population in Mahlavu cells significantly (Fig. 7a). Besides, sorafenib was known to enrich the LCSC population as demonstrated previously [36]. To test the combinatory effect of compound $7 \mathrm{~b}$ with Sorafenib, Huh7 cells were treated with the increasing concentrations of both compounds simultaneously for $72 \mathrm{~h}$. Both flow cytometry analysis and the sphere formation assay have shown that compound $7 \mathrm{~b}$ alone and, in combination with sorafenib, reduced the LCSC ratio, and the sphere formation capacity of Huh7 cells. (Fig. 7b).

\section{Effect of compound $7 \mathrm{~b}$ on cell migration}

To identify the effect of compound $7 \mathrm{~b}$ on the migration capacity of $\mathrm{HCC}$ cells, a real-time cell migration system (RT-CES, DP system, xCELLigence) was used. Huh7 and Mahlavu cells were treated with Taxol as a positive control for cell migration inhibition or with compound 7b (Huh7: $2 \mu \mathrm{M}$, Mahlavu: $8 \mu \mathrm{M}$ ) for 24 hours. Comparable with the effect of Taxol, compound $7 \mathbf{b}$ inhibited the migration of both cell lines 
compared to the DMSO treated cells (Fig. 7c). Altogether, it was concluded that 7b could effectively interfere with the drug resistance-related cellular mechanisms such as stemness and migration.

\section{Discussion}

$\mathrm{HCC}$ is one of the most common and deadly cancers in the world. Sorafenib, which is a multi-kinase inhibitor approved by FDA was reported to prolong survival of advanced stage HCC patients by only 3 months [50]. Although second-line treatment options such as Regorafenib were also studied for patients who are intolerant to sorafenib, drug resistance has become a critical problem for these patients due to the highly heterogeneous molecular nature of HCC.

Recent studies have reported that NSAIDs effectively decrease the incidence and mortality of various types of cancers $[12,51,52]$. In this study, we demonstrated that compound $7 \mathrm{~b}$, a synthetic $1,2,4-$ triazolo[3,4-b]-1,3,4-thiadiazine NSAID derivative, is a potent anticancer agent for HCC cells in vitro and in vivo, which was previously reported to have promising analgesic and anti-inflammatory activities $[25,29]$. Among the reported numerous biological effects, accumulation of reactive oxygen species (ROS) is considered as the underlying mechanism of the anticancer potential of NSAIDs [53,54]. Compatible with the literature, we have demonstrated that ROS accumulation induces growth inhibition, apoptosis, and G2/M cell cycle arrest in the presence of $7 \mathrm{~b}$ (Fig. 3, and Fig. 4). We also examined signaling pathways activated by oxidative stress and found that and found that activation of JNK and p38 as well as the downstream protein c-Jun was induced upon $7 \mathrm{~b}$ treatment in HCC cells. (Fig. 5a). Further analysis of the upstream components of the JNK pathway revealed that compound $\mathbf{7 b}$ treatment causes cell line-specific activation of MKK7 protein (Fig. 5b) as well as dynamic regulation of phosphorylation sites on the ASK1 protein (Fig. 5b). Our in vivo data supported our findings on anticancer activity of $7 \mathrm{~b}$, where orally administered compound increased the overall disease-free survival for more than 4 months and reduced tumor size significantly in Mahlavu xenografts in nude mice (Fig. 6).

One of the most important factors associated with drug resistance in HCC is the presence of cancer stem cells. Conventional therapies fail to affect slowly dividing stem cell-like cancer cells and mainly target rapidly dividing tumor cells [55]. CSCs can reconstitute the tumor by themselves and manage to acquire metastatic features to migrate to distant organs $[56,57]$. Hence, we have also tested the compounds against LCSC and revealed that compound $7 \mathrm{~b}$ was also effective in inhibiting the enrichment of LCSCs (Fig. 7), meaning that compound $7 \mathrm{~b}$ is not solely active on tumor cells (non-stem), but also tumorinitiating cells in HCC. We also tested the effect of compound $7 \mathrm{~b}$ on the migration capacity of HCC cells, since CSC activity is associated with the migration and metastatic capacity of cancer cells [58]. It was shown that $7 \mathrm{~b}$ could effectively inhibit the migration of Huh7 and Mahlavu cells, comparable to the effect of Taxol, which is known as a microtubule stabilizing agent [59] that is widely used as a positive control for inhibition of migration in cancer cells [60,61].

In the last decade, the anticancer and anti-metastatic effects of a well-defined NSAID, Aspirin, has been described in cancer including HCC [62]. It is reported that by the induction of metabolic and oxidative 
stress in HepG2 cells, aspirin causes apoptosis through mitochondrial dysfunction [63]. In another study, aspirin was shown to attenuate pro-metastasis caused by sorafenib by upregulating the tumor suppressor HTATIP2 in nude mice xenografts [64]. Yet, the use of aspirin in treatment of cancer and its prevention remains uncertain due to the problems with the optimal dosage of aspirin and its serious sideeffects such as gastrointestinal bleeding, increased uric acid, and coagulation inhibition $[65,66]$. Since these drugs are not designed to treat or prevent cancer progression, designing and developing novel NSAIDs that target cancer-related mechanisms is very crucial and can be considered as a new class of anticancer pharmaceutical agents such as non-steroid anti-inflammatory chemotherapeutic drugs (NSAICD).

In conclusion, our results revealed that 7b, a synthetic 1,2,4-triazolo[3,4-b]-1,3,4-thiadiazine NSAID derivative, is a promising compound with anticancer and anti-stem cell activities against HCC cells in vitro and in vivo. The anticancer effect was attributed to the induction of oxidative stress, cell cycle arrest, and eventually apoptosis through the JNK pathway regulation. These findings highlight the potency of $7 \mathrm{~b}$ as a new NSAICD, bearing a thiadiazine core, to be considered a promising anticancer drug for HCC patients and deserves further analysis.

\section{Abbreviations}

HCC, hepatocellular carcinoma; NSAID, nonsteroidal anti-inflammatory drug; ROS, reactive oxygen species; SRB, sulforhodamine B; DMSO, dimethyl sulfoxide; LCSC, liver cancer stem cell; RT, room temperature; IC50, 50 \% inhibitory concentration; DMEM, Dulbecco's Modified Eagle Medium; FBS, fetal bovine serum; PBS, phosphate-buffered saline; $\mathrm{Cl}$ (cell index) RT-PCR, real-time polymerase chain reaction; Se, Selenium; DCFH-DA, dichloro-dihydro-fluorescein diacetate.

\section{Declarations}

\section{Acknowledgments}

This work was supported by The Scientific and Technological Research Council of Turkey Grant \#112S030 and The Turkish Ministry of Development project \#2016K121540. We would like to thank Dr. Aybar Can Acar for his valuable contribution to KanSiL infrastructure grant, and Tugce Oksakli for laboratory technical assistance.

\section{Author contributions}

BT and RCA participated in research design and supervised the study. DCK, EBG, and PA performed the experiments. GA guided and contributed to the in vivo experiments. DCK, EBG and RCA analyzed the data. $\mathrm{DCK}, \mathrm{BT}$, and RCA prepared the figures and contributed to the writing of the manuscript.

Competing interests: The authors declare no competing interests. 


\section{References}

1. Villanueva, A. Hepatocellular Carcinoma. N Engl J Med380, 1450-1462, doi:10.1056/NEJMra1713263 (2019).

2. Jeng, K. S. et al. Heterogeneity of hepatocellular carcinoma contributes to cancer progression. Crit Rev Oncol Hemato/94, 337-347, doi:10.1016/j.critrevonc.2015.01.009 (2015).

3. Finn, R. S. Emerging targeted strategies in advanced hepatocellular carcinoma. Semin Liver Dis33 Suppl 1, S11-19, doi:10.1055/s-0033-1333632 (2013).

4. Gong, X. L. \& Qin, S. K. Progress in systemic therapy of advanced hepatocellular carcinoma. World J Gastroentero/22, 6582-6594, doi:10.3748/wjg.v22.i29.6582 (2016).

5. Frager, S. Z. \& Schwartz, J. M. Hepatocellular Carcinoma: Epidemiology, Screening, and Assessment of Hepatic Reserve. Curr Onco/27, 138-143, doi:10.3747/co.27.7181 (2020).

6. Llovet, J. M. et al. Hepatocellular carcinoma. Nat Rev Dis Primers7, 6, doi:10.1038/s41572-02000240-3 (2021).

7. Llovet, J. M. et al. Sorafenib in advanced hepatocellular carcinoma. N Engl J Med359, 378-390, doi:10.1056/NEJMoa0708857 (2008).

8. Kim, K. et al. Regorafenib in advanced hepatocellular carcinoma (HCC): considerations for treatment. Cancer Chemother Pharmaco/80, 945-954, doi:10.1007/s00280-017-3431-5 (2017).

9. Deng, G. L., Zeng, S. \& Shen, H. Chemotherapy and target therapy for hepatocellular carcinoma: New advances and challenges. World J Hepatol7, 787-798, doi:10.4254/wjh.v7.i5.787 (2015).

10. Yeo, W. et al. A randomized phase III study of doxorubicin versus cisplatin/interferon alpha2b/doxorubicin/fluorouracil (PIAF) combination chemotherapy for unresectable hepatocellular carcinoma. J Natl Cancer Inst97, 1532-1538, doi:10.1093/jnci/dji315 (2005).

11. Tang, W. et al. The mechanisms of sorafenib resistance in hepatocellular carcinoma: theoretical basis and therapeutic aspects. Signal Transduct Target Ther5, 87, doi:10.1038/s41392-020-0187-x (2020).

12. Rayburn, E. R., Ezell, S. J. \& Zhang, R. Anti-Inflammatory Agents for Cancer Therapy. Mol Cell Pharmaco/1, 29-43, doi:10.4255/mcpharmacol.09.05 (2009).

13. Aytac, P. S. et al. Novel triazolothiadiazines act as potent anticancer agents in liver cancer cells through Akt and ASK-1 proteins. Bioorg Med Chem24, 858-872, doi:10.1016/j.bmc.2016.01.013 (2016).

14. Greenspan, E. J., Madigan, J. P., Boardman, L. A. \& Rosenberg, D. W. Ibuprofen inhibits activation of nuclear \{beta\}-catenin in human colon adenomas and induces the phosphorylation of GSK-3\{beta\}. Cancer Prev Res (Phila)4, 161-171, doi:10.1158/1940-6207.CAPR-10-0021 (2011).

15. Kim, M. S. et al. Naproxen induces cell-cycle arrest and apoptosis in human urinary bladder cancer cell lines and chemically induced cancers by targeting PI3K. Cancer Prev Res (Phila)7, 236-245, doi:10.1158/1940-6207.CAPR-13-0288 (2014). 
16. Santen, R. J. Inhibition of aromatase: insights from recent studies. Steroids68, 559-567, doi:10.1016/S0039-128x(03)00096-5 (2003).

17. Goss, P. E. \& Strasser-Weippl, K. Aromatase inhibitors for chemoprevention. Best Pract Res Cl En18, 113-130, doi:Doi 10.1016/S1521-690x(03)00070-8 (2004).

18. Albrecht, B. K. et al. Discovery and optimization of triazolopyridazines as potent and selective inhibitors of the c-Met kinase. J Med Chem51, 2879-2882, doi:10.1021/jm800043g (2008).

19. Boezio, A. A. et al. Discovery and optimization of potent and selective triazolopyridazine series of cMet inhibitors. Bioorg Med Chem Lett19, 6307-6312, doi:10.1016/j.bmcl.2009.09.096 (2009).

20. Bhat, K. S. et al. Synthesis and antitumor activity studies of some new fused 1,2,4-triazole derivatives carrying 2,4-dichloro-5-fluorophenyl moiety. Eur J Med Chem44, 5066-5070, doi:10.1016/j.ejmech.2009.09.010 (2009).

21. Ibrahim, D. A. Synthesis and biological evaluation of 3,6-disubstituted [1,2,4]triazolo[3,4-b] $[1,3,4]$ thiadiazole derivatives as a novel class of potential anti-tumor agents. Eur J Med Chem44, 2776-2781, doi:10.1016/j.ejmech.2009.01.003 (2009).

22. Sunil, D. et al. Synthesis, characterization, antioxidant, and anticancer studies of 6-[3-(4chlorophenyl)-1H-pyrazol-4-yl]-3-[(2-naphthyloxy)methyl][1,2,4]triazolo[3,4-b][1,3,4]thiadiazole in HepG2 cell lines. Med Chem Res20, 1074-1080, doi:10.1007/s00044-010-9436-9 (2011).

23. Khan, I. et al. Synthesis, crystal structure and biological evaluation of some novel 1,2,4-triazolo[3,4b]-1,3,4-thiadiazoles and 1,2,4-triazolo[3,4-b]-1,3,4-thiadiazines. Eur J Med Chem78, 167-177, doi:10.1016/j.ejmech.2014.03.046 (2014).

24. Tozkoparan, B. et al. Novel 1,2,4-Triazolo[3,4-b]-1,3,4-thiadiazole Derivatives as Dual Analgesic/Antiinflammatory and Antimicrobial Agents. Lett Drug Des Discov9, 204-212, doi:Doi 10.2174/157018012799079626 (2012).

25. Tozkoparan, B., Aytac, S. P. \& Aktay, G. Novel 3,6-Disubstituted 7H-1,2,4-Triazolo[3,4-b] $[1,3,4]$ thiadiazines: Synthesis, Characterization, and Evaluation of Analgesic/Anti-inflammatory, Antioxidant Activities. Arch Pharm342, 291-298, doi:10.1002/ardp.200800188 (2009).

26. Bishayee, A. The role of inflammation and liver cancer. Adv Exp Med Bio/816, 401-435, doi:10.1007/978-3-0348-0837-8_16 (2014).

27. Radwan, R. R., Zaher, N. H. \& El-Gazzar, M. G. Novel 1,2,4-triazole derivatives as antitumor agents against hepatocellular carcinoma. Chem-Biol Interact274, 68-79, doi:10.1016/j.cbi.2017.07.008 (2017).

28. Tuncbilek, M., Guven, E. B., Onder, T. \& Cetin Atalay, R. Synthesis of novel 6-(4-substituted piperazine1-yl)-9-(beta-D-ribofuranosyl)purine derivatives, which lead to senescence-induced cell death in liver cancer cells. J Med Chem55, 3058-3065, doi:10.1021/jm3001532 (2012).

29. Aytac, S. P. et al. Synthesis of 3,6-disubstituted 7H-1,2,4-triazolo[3,4-b]-1,3,4-thiadiazines as novel analgesic/anti-inflammatory compounds. Eur J Med Chem44, 4528-4538, doi:10.1016/j.ejmech.2009.06.026 (2009). 
30. Oefinger, P. E., Bronson, D. L. \& Dreesman, G. R. Induction of hepatitis B surface antigen in human hepatoma-derived cell lines. J Gen Viro/53, 105-113, doi:10.1099/0022-1317-53-1-105 (1981).

31. He, L. et al. Establishment and characterization of a new human hepatocellular carcinoma cell line. In Vitro20, 493-504, doi:10.1007/BF02619623 (1984).

32. Onen-Bayram, F. E. et al. A novel thiazolidine compound induces caspase-9 dependent apoptosis in cancer cells. Bioorg Med Chem20, 5094-5102, doi:10.1016/j.bmc.2012.07.016 (2012).

33. Hawash, M. M. et al. Synthesis and biological evaluation of novel pyrazolic chalcone derivatives as novel hepatocellular carcinoma therapeutics. Eur J Med Chem129, 12-26, doi:10.1016/j.ejmech.2017.02.002 (2017).

34. Irmak, M. B., Ince, G., Ozturk, M. \& Cetin-Atalay, R. Acquired tolerance of hepatocellular carcinoma cells to selenium deficiency: a selective survival mechanism? Cancer Res63, 6707-6715 (2003).

35. Durmaz, I. et al. Liver cancer cells are sensitive to Lanatoside $C$ induced cell death independent of their PTEN status. Phytomedicine23, 42-51, doi:10.1016/j.phymed.2015.11.012 (2016).

36. Kahraman, D. C. et al. Quinoides and VEGFR2 TKIs influence the fate of hepatocellular carcinoma and its cancer stem cells. Medchemcomm8, 81-87, doi:10.1039/c6md00392c (2017).

37. Kahraman, D. C., Kahraman, T. \& Cetin-Atalay, R. Targeting PI3K/Akt/mTOR Pathway Identifies Differential Expression and Functional Role of IL8 in Liver Cancer Stem Cell Enrichment. Mol Cancer Ther18, 2146-2157, doi:10.1158/1535-7163.MCT-19-0004 (2019).

38. Shi, Y. et al. ROS-dependent activation of JNK converts p53 into an efficient inhibitor of oncogenes leading to robust apoptosis. Cell Death Differ21, 612-623, doi:10.1038/cdd.2013.186 (2014).

39. Redza-Dutordoir, M. \& Averill-Bates, D. A. Activation of apoptosis signalling pathways by reactive oxygen species. Biochim Biophys Acta1863, 2977-2992, doi:10.1016/j.bbamcr.2016.09.012 (2016).

40. van Schadewijk, A., van't Wout, E. F., Stolk, J. \& Hiemstra, P. S. A quantitative method for detection of spliced X-box binding protein-1 (XBP1) mRNA as a measure of endoplasmic reticulum (ER) stress. Cell Stress Chaperones17, 275-279, doi:10.1007/s12192-011-0306-2 (2012).

41. Oslowski, C. M. \& Urano, F. Measuring ER stress and the unfolded protein response using mammalian tissue culture system. Methods Enzymo/490, 71-92, doi:10.1016/B978-0-12-3851147.00004-0 (2011).

42. Gutierrez, G. J. et al. JNK-mediated phosphorylation of Cdc25C regulates cell cycle entry and G(2)/M DNA damage checkpoint. J Biol Chem285, 14217-14228, doi:10.1074/jbc.M110.121848 (2010).

43. MacCorkle, R. A. \& Tan, T. H. Mitogen-activated protein kinases in cell-cycle control. Cell Biochem Biophys43, 451-461, doi:10.1385/CBB:43:3:451 (2005).

44. Min, L., He, B. \& Hui, L. Mitogen-activated protein kinases in hepatocellular carcinoma development. Semin Cancer Bio/21, 10-20, doi:10.1016/j.semcancer.2010.10.011 (2011).

45. Haeusgen, W., Herdegen, T. \& Waetzig, V. The bottleneck of JNK signaling: molecular and functional characteristics of MKK4 and MKK7. Eur J Cell Bio/90, 536-544, doi:10.1016/j.ejcb.2010.11.008 (2011). 
46. Shiizaki, S., Naguro, I. \& Ichijo, H. Activation mechanisms of ASK1 in response to various stresses and its significance in intracellular signaling. Adv Biol Regu/53, 135-144, doi:10.1016/j.jbior.2012.09.006 (2013).

47. Hattori, K., Naguro, I., Runchel, C. \& Ichijo, H. The roles of ASK family proteins in stress responses and diseases. Cell Commun Signa/7, 9, doi:10.1186/1478-811X-7-9 (2009).

48. Buontempo, F. et al. Inhibition of Akt signaling in hepatoma cells induces apoptotic cell death independent of Akt activation status. Invest New Drugs29, 1303-1313, doi:10.1007/s10637-0109486-3 (2011).

49. Cheng, Z., Li, X. \& Ding, J. Characteristics of liver cancer stem cells and clinical correlations. Cancer Lett379, 230-238, doi:10.1016/j.canlet.2015.07.041 (2016).

50. Bruix, J., da Fonseca, L. G. \& Reig, M. Insights into the success and failure of systemic therapy for hepatocellular carcinoma. Nat Rev Gastroenterol Hepato/16, 617-630, doi:10.1038/s41575-019-0179$x(2019)$.

51. Roxburgh, C. S. \& McMillan, D. C. Cancer and systemic inflammation: treat the tumour and treat the host. Br J Cancer110, 1409-1412, doi:10.1038/bjc.2014.90 (2014).

52. Zappavigna, S. et al. Anti-Inflammatory Drugs as Anticancer Agents. Int J Mol Sci21, doi:10.3390/ijms21072605 (2020).

53. Adachi, M. et al. Nonsteroidal anti-inflammatory drugs and oxidative stress in cancer cells. Histol Histopathol22, 437-442, doi:10.14670/HH-22.437 (2007).

54. Tinsley, H. N. et al. New NSAID targets and derivatives for colorectal cancer chemoprevention. Recent Results Cancer Res191, 105-120, doi:10.1007/978-3-642-30331-9_6 (2013).

55. Senthebane, D. A. et al. The Role of Tumor Microenvironment in Chemoresistance: To Survive, Keep Your Enemies Closer. Int J Mol Sci18, doi:10.3390/ijms18071586 (2017).

56. Oishi, N. \& Wang, X. W. Novel therapeutic strategies for targeting liver cancer stem cells. Int J Biol Scl7, 517-535 (2011).

57. Yamashita, T. \& Kaneko, S. Liver cancer stem cells: Recent progress in basic and clinical research. Regen Ther17, 34-37, doi:10.1016/j.reth.2021.03.002 (2021).

58. Schulte, L. A., Lopez-Gil, J. C., Sainz, B., Jr. \& Hermann, P. C. The Cancer Stem Cell in Hepatocellular Carcinoma. Cancers (Basel)12, doi:10.3390/cancers12030684 (2020).

59. Belotti, D. et al. The microtubule-affecting drug paclitaxel has antiangiogenic activity. Clin Cancer Res2, 1843-1849 (1996).

60. Kuljittichanok, D. et al. Effect of Derris scandens extract on a human hepatocellular carcinoma cell line. Oncol Lett16, 1943-1952, doi:10.3892/ol.2018.8824 (2018).

61. Wang, X. et al. In vitro wound healing of tumor cells: inhibition of cell migration by selected cytotoxic alkaloids. BMC Pharmacol Toxico/20, 4, doi:10.1186/s40360-018-0284-4 (2019).

62. Zhang, Z., Chen, F. \& Shang, L. Advances in antitumor effects of NSAIDs. Cancer Manag Res10, 4631-4640, doi:10.2147/CMAR.S175212 (2018). 
63. Raza, H., John, A. \& Benedict, S. Acetylsalicylic acid-induced oxidative stress, cell cycle arrest, apoptosis and mitochondrial dysfunction in human hepatoma HepG2 cells. Eur J Pharmaco/668, 1524, doi:10.1016/j.ejphar.2011.06.016 (2011).

64. Lu, L. et al. Aspirin minimized the pro-metastasis effect of sorafenib and improved survival by upregulating HTATIP2 in hepatocellular carcinoma. Plos One8, e65023, doi:10.1371/journal.pone.0065023 (2013).

65. Huang, E. S. et al. Long-term use of aspirin and the risk of gastrointestinal bleeding. Am J Med124, 426-433, doi:10.1016/j.amjmed.2010.12.022 (2011).

66. Li, Z. et al. Effects of aspirin on the gastrointestinal tract: Pros vs. cons. Oncol Lett20, 2567-2578, doi:10.3892/ol.2020.11817 (2020).

\section{Figures}
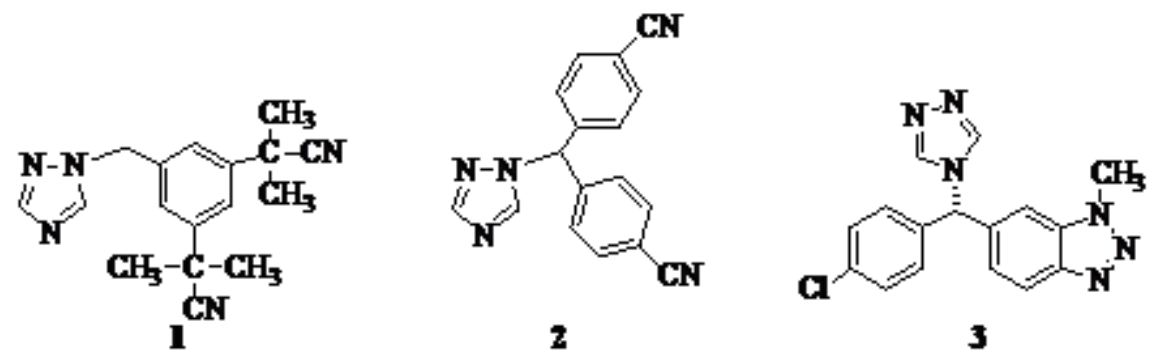

Figure 1

Structures of anastrozole, letrozole, and vorozole used in treatment of estrogen receptor positive breast cancer as nonsteroidal aromatase inhibitors.
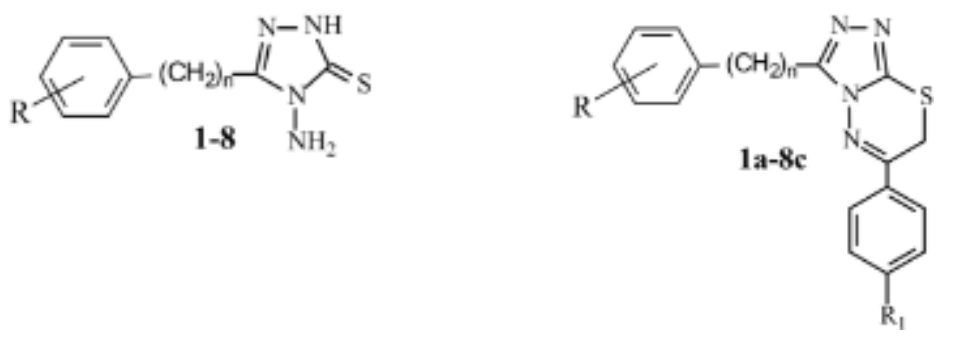

Figure 2

The chemical structure of the compounds studied. 
a
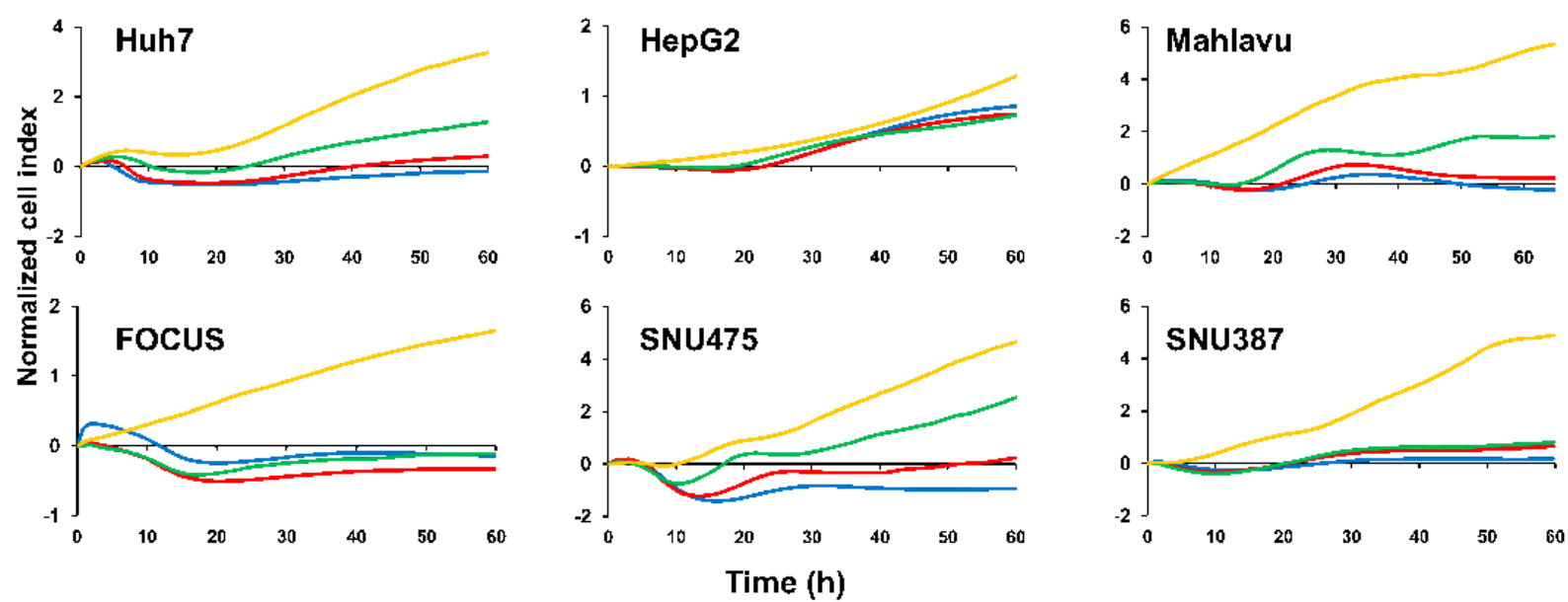

$-4.0 \mu \mathrm{M} \quad-2.0 \mu \mathrm{M}-1.0 \mu \mathrm{M}-\mathrm{DMSO}$

b

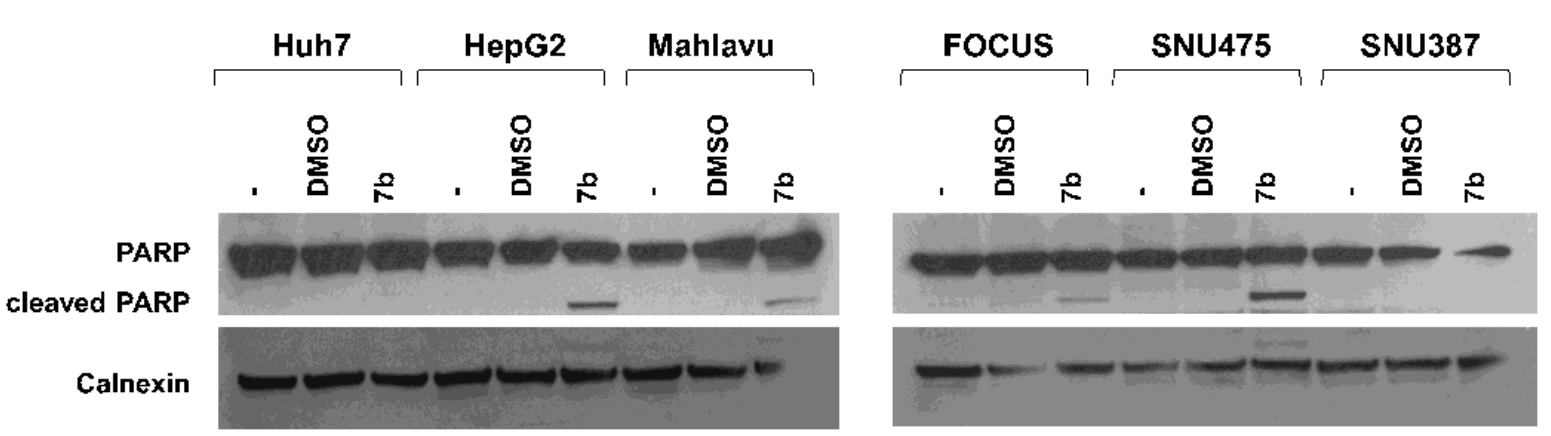

C

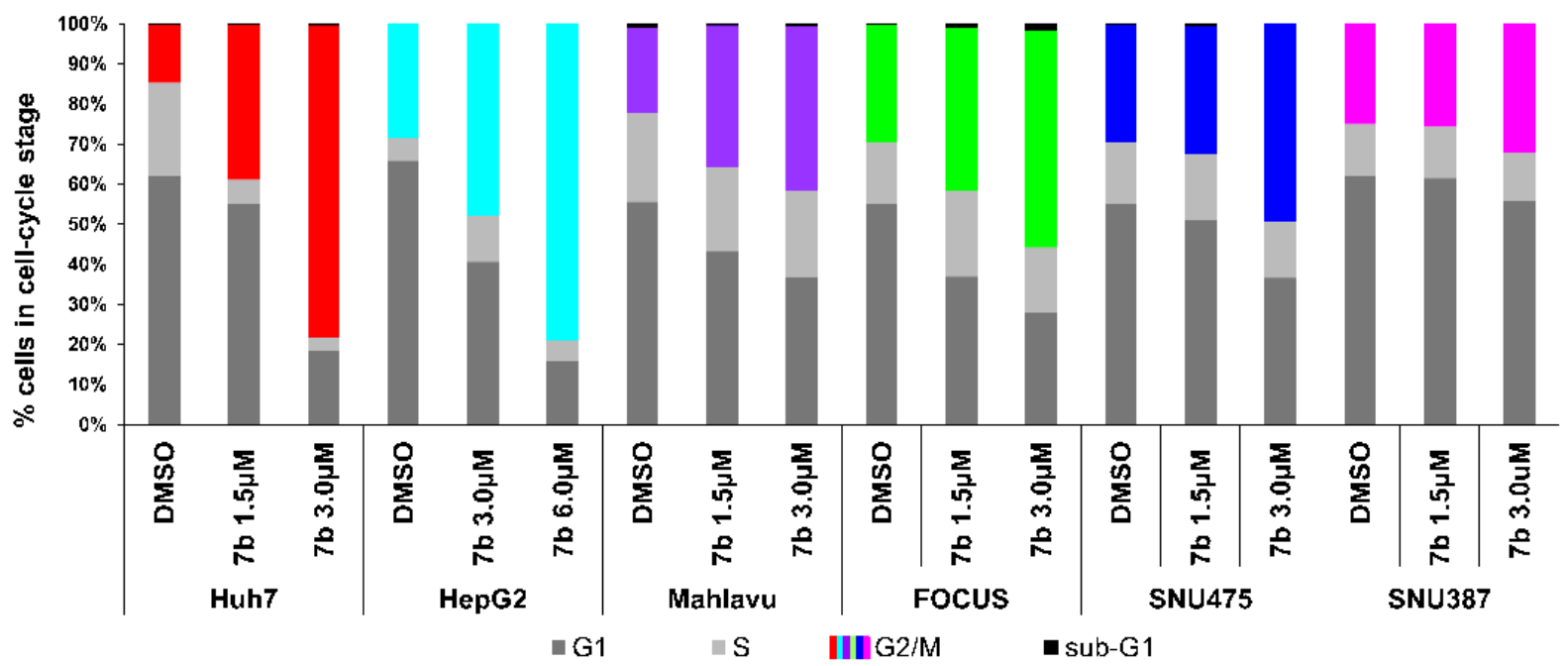

Figure 3

7b induces growth inhibition, apoptosis, and cell cycle arrest in HCC cell lines. (a) Real-time cell growth in the presence of compound $7 \mathrm{~b}$ and its DMSO control. The cell growth index of $7 \mathrm{~b}$ treated cells were recorded every 30 minutes. All compounds were administered in triplicates for RT-CES analysis. (b) Western blot analysis displaying the cleaved PARP upon compound 7b treatment. All HCC cell lines were treated with $2.5 \square \mathrm{M} 7 \mathrm{~b}$ or its corresponding DMSO for $24 \mathrm{~h}$. Calnexin protein was used as an equal loading 
control. Full-length blots/gels are presented in Supplementary Figure S1. (c) Bar graphs indicating cell cycle distribution of Huh7, HepG2, Mahlavu, FOCUS, SNU475 and SNU387 cells treated with increasing concentrations of compound 7b and their DMSO controls for $24 \mathrm{~h}$.

a

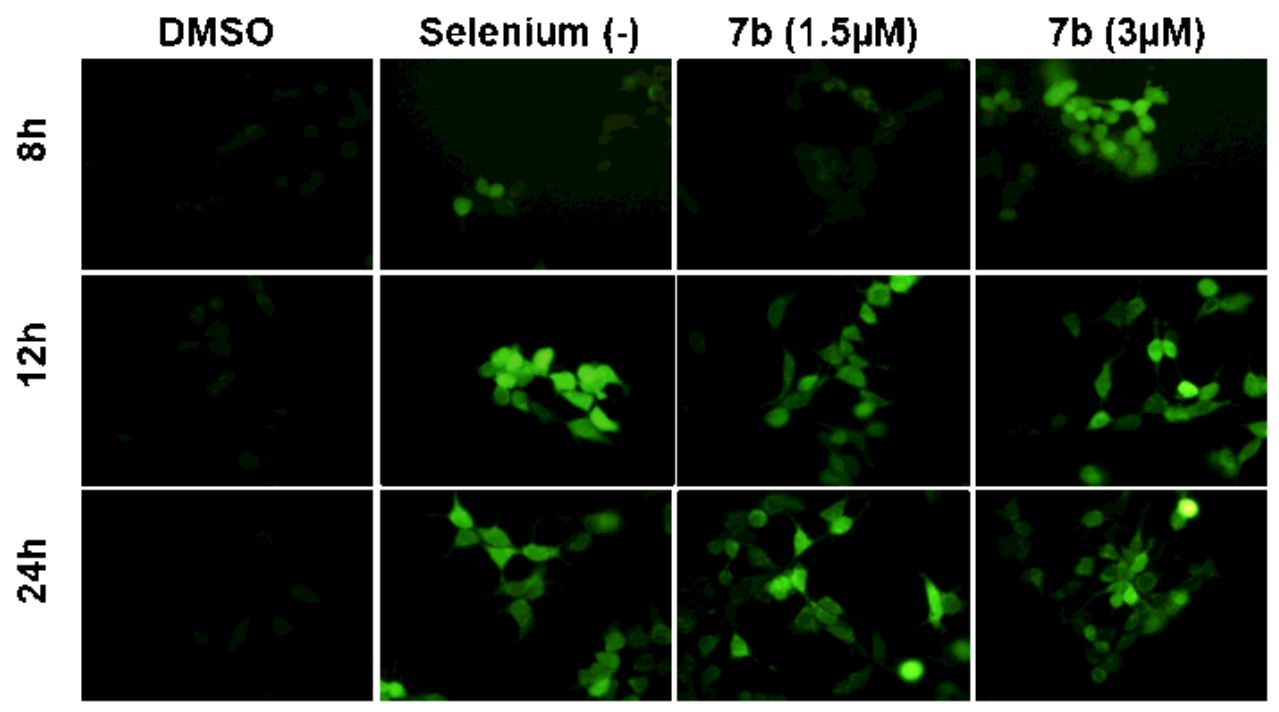

\section{Mahlavu}

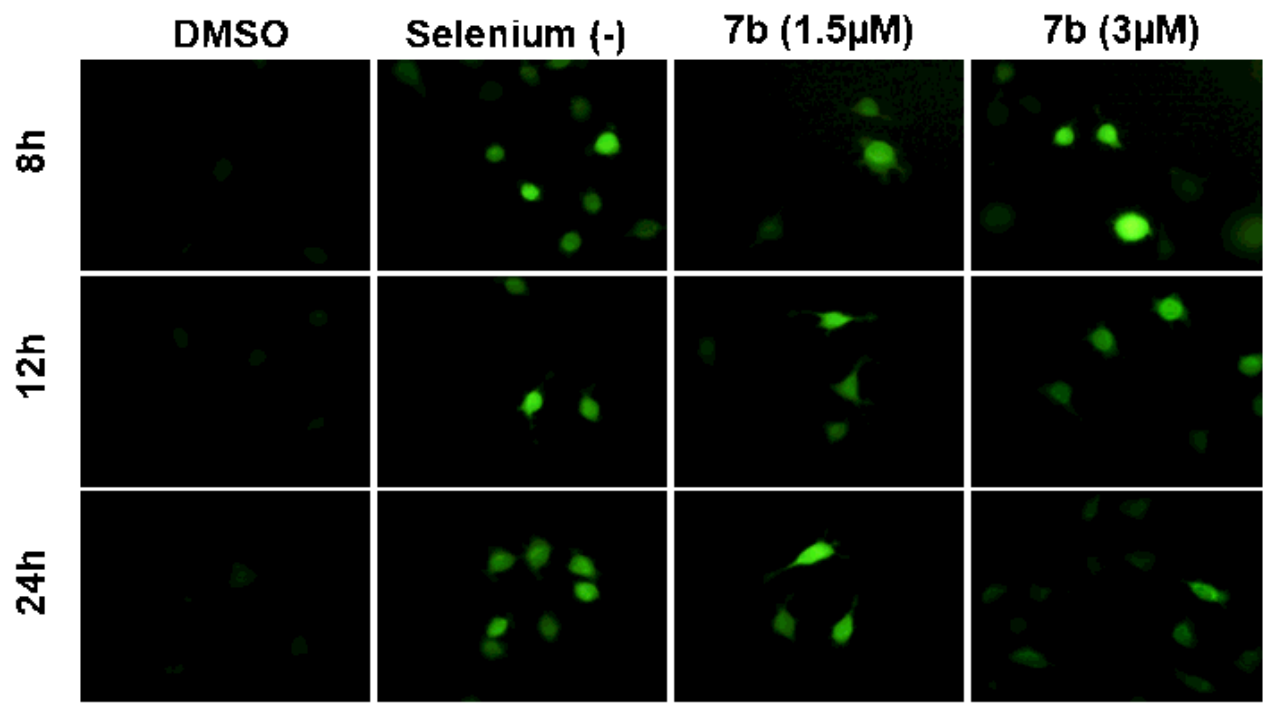

b
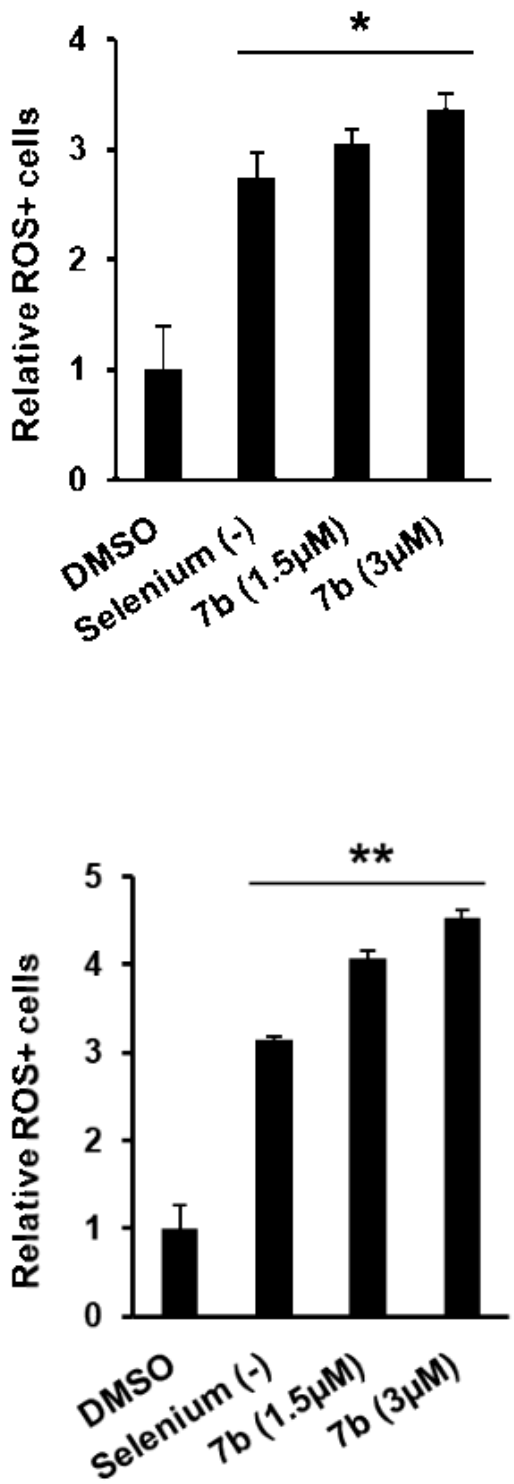

Figure 4

7b induces oxidative stress in HCC cell lines. (a) Representative images of DCFH-DA staining of Huh7 and Mahlavu cells treated with Se-deficient media or increasing concentrations of $7 \mathrm{~b}$ for 8,12 , and $24 \mathrm{~h}$. All images are obtained under a fluorescent microscope with 20x magnification. (b) Flow cytometric analysis of ROS accumulation in HCC cells. Bar graphs indicate the fold change and quantitative analysis of ROS positive cells relative to DMSO after $12 \mathrm{~h}$ for each treatment condition. Se-deficient medium was used as a positive control for ROS induction. 
a
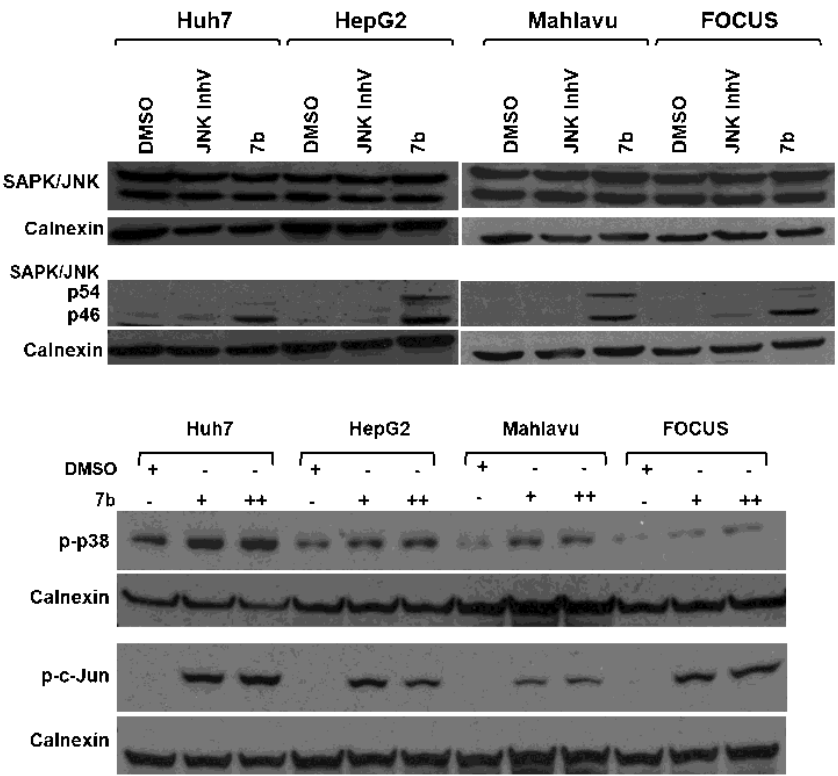

b
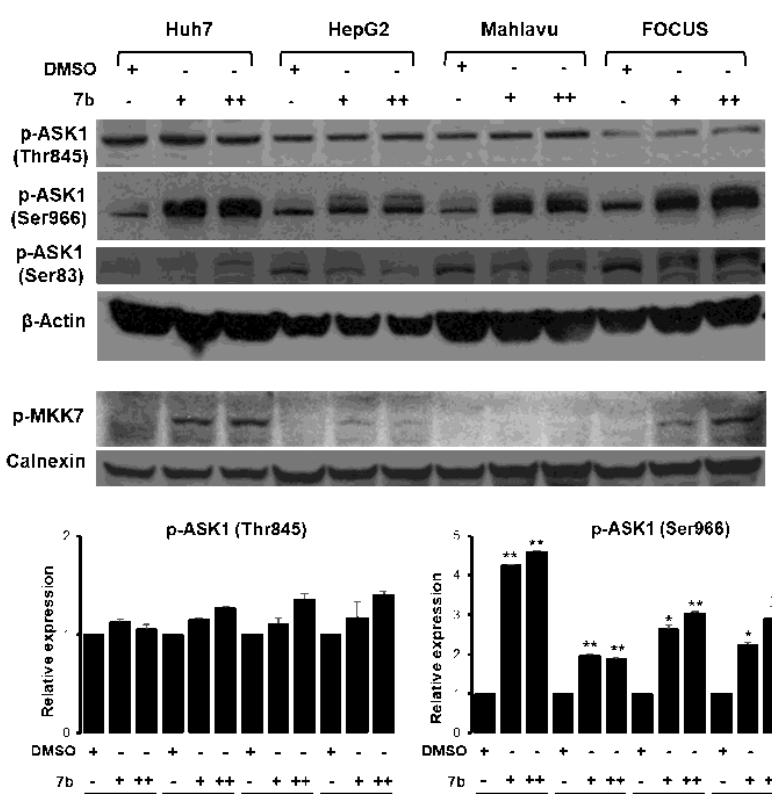

$\frac{-+++}{\text { Huh7 }} \frac{-+++}{\text { Hepgz }} \frac{-+++}{\text { Mahlavu }} \frac{-+++}{\text { FOCUS }}$
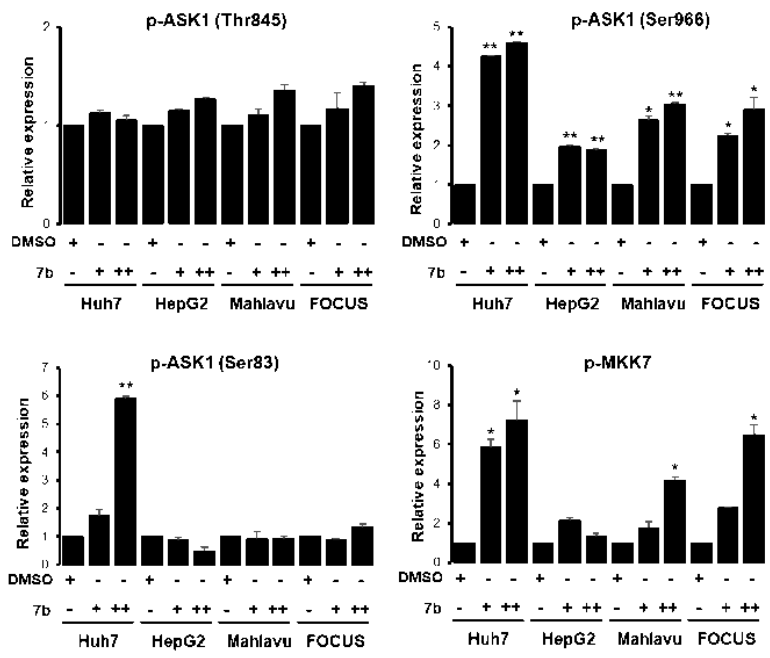

$\mathrm{p} \sim \mathrm{JNK}(\mathrm{p} 54)$
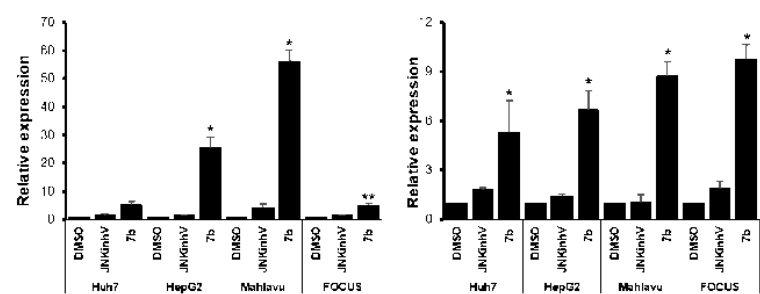
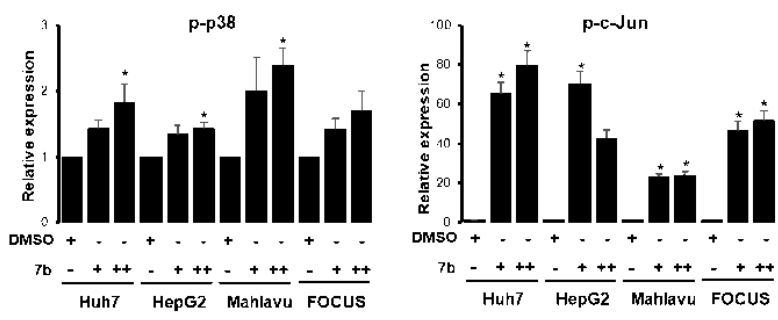

C

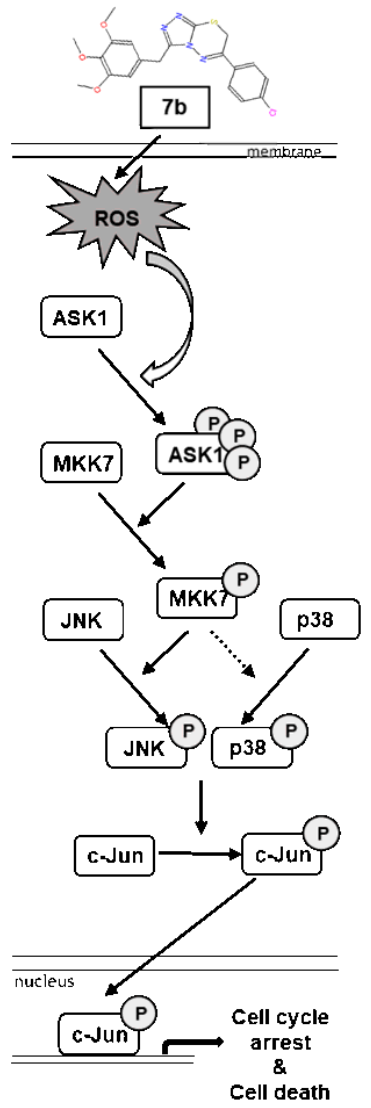

Figure 5

7b activates JNK pathway in HCC cell lines. (a) Representative western blot images of total or active (phosphorylated) JNK1, JNK2 protein levels in HCC cell lines treated with increasing concentrations of

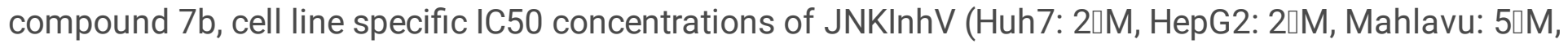
FOCUS: 0.5ロM), and DMSO control (top left panel); phospho-p38 and phospho-c-Jun levels in HCC cell lines treated with increasing concentrations of 7b (+: IC50, ++: 2x IC50) and DMSO control (bottom left) 
for $24 \mathrm{~h}$. Bar graphs represent quantitative analysis of the relative band intensity values obtained from 3 different experiments of each treatment group for phosphorylated JNK, phosphorylated c-Jun proteins compared to DMSO using ImageJ analysis tool (right panel). (b) Representative images indicate the changes in the levels of P-MKK7, P-ASK1Thr845, P-ASK1Ser966 and P-ASK1Ser83 proteins by western blot analysis. Huh7, HepG2, Mahlavu, and FOCUS cells were treated with increasing concentrations of compound $7 \mathrm{~b}$ and corresponding DMSO for $24 \mathrm{~h}$ (bottom left panel). Bar graphs represent quantitative analysis of the relative band intensity values obtained from 3 different experiments of each treatment group for MKK-7, and phosphorylated ASK1 proteins compared to DMSO using ImageJ analysis tool (right panel). Calnexin or $\beta$-actin were used as equal loading controls for all western blot experiments. Full-length blots/gels are presented in Supplementary Figure S1 (c) Illustration of molecular mechanisms involved in response to compound $7 \mathrm{~b}$ treatment in $\mathrm{HCC}$ cells. Compound $7 \mathrm{~b}$ induces oxidative stress, which activates the ASK1/MKK7/JNK/c-Jun pathway. Translocation of phosphorylated c-Jun into the nucleus results in the transcription of genes responsible for the induction of cell cycle arrest, and eventually apoptosis in HCC cells. 
a
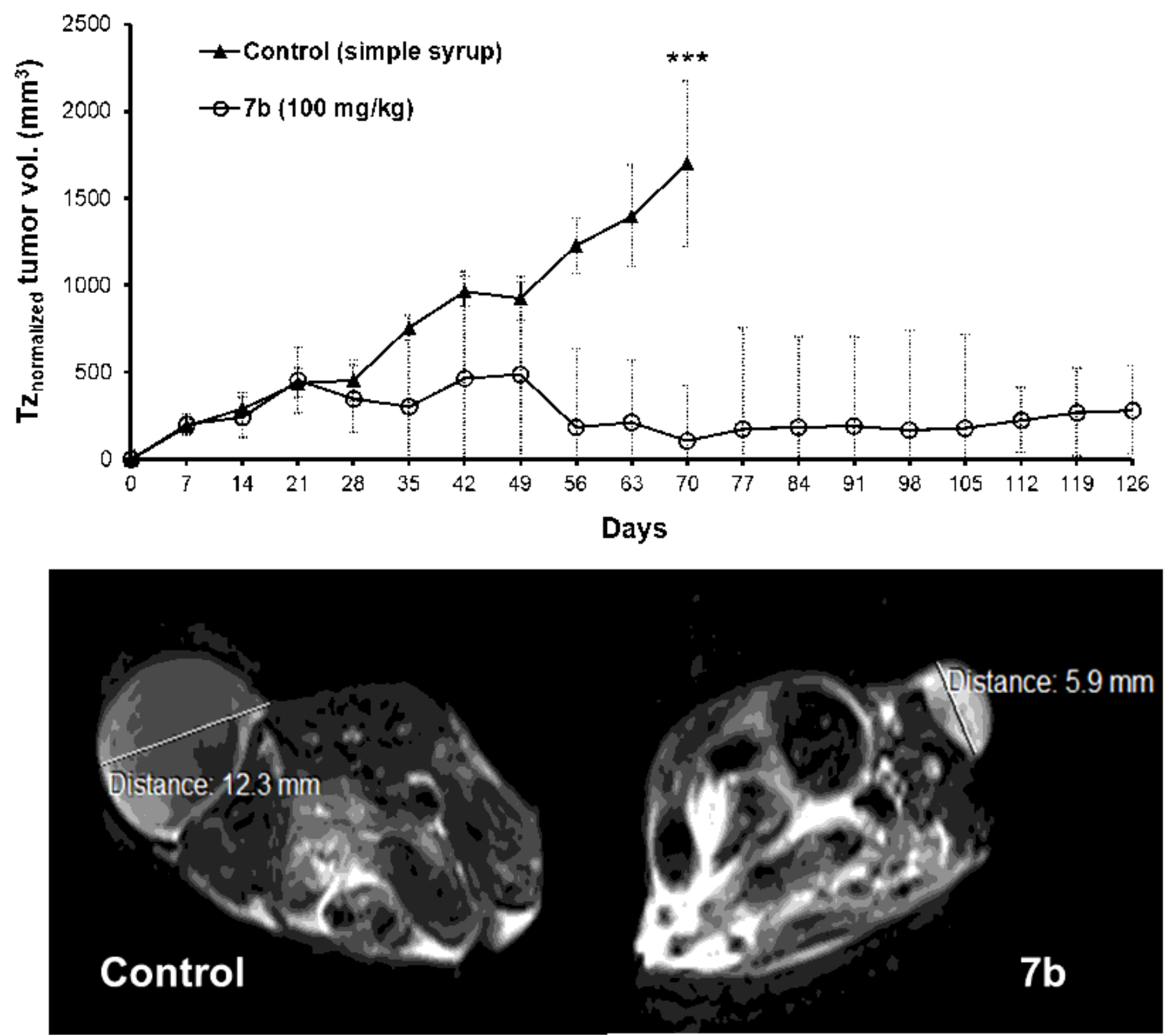

Figure 6

$7 \mathrm{~b}$ reduces tumor growth and increases overall survival of nude mice. (a) Mahlavu xenografted nude mice were treated with $(100 \mathrm{mg} / \mathrm{kg})$ compound $7 \mathrm{~b}$ prepared in simple syrup or simple syrup-only twice a week once the tumor size reached a volume of $150 \mathrm{~mm} 3$. Tumor sizes are recorded twice a week throughout the experiment. Time-zero normalized data are shown as mean \pm SD for each group of animals $(n=5) ; * \star * P<0.001$, as calculated using one-way ANOVA (b) Representative MRI images taken at the 135th day for compound $7 \mathrm{~b}$ treated group and 105th day for control. 
a

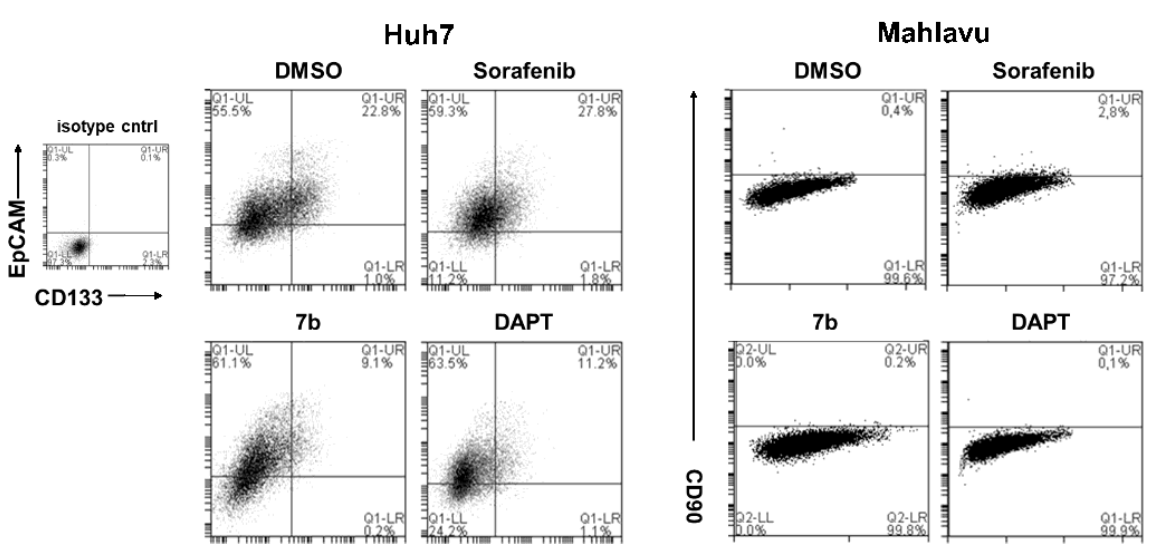

b
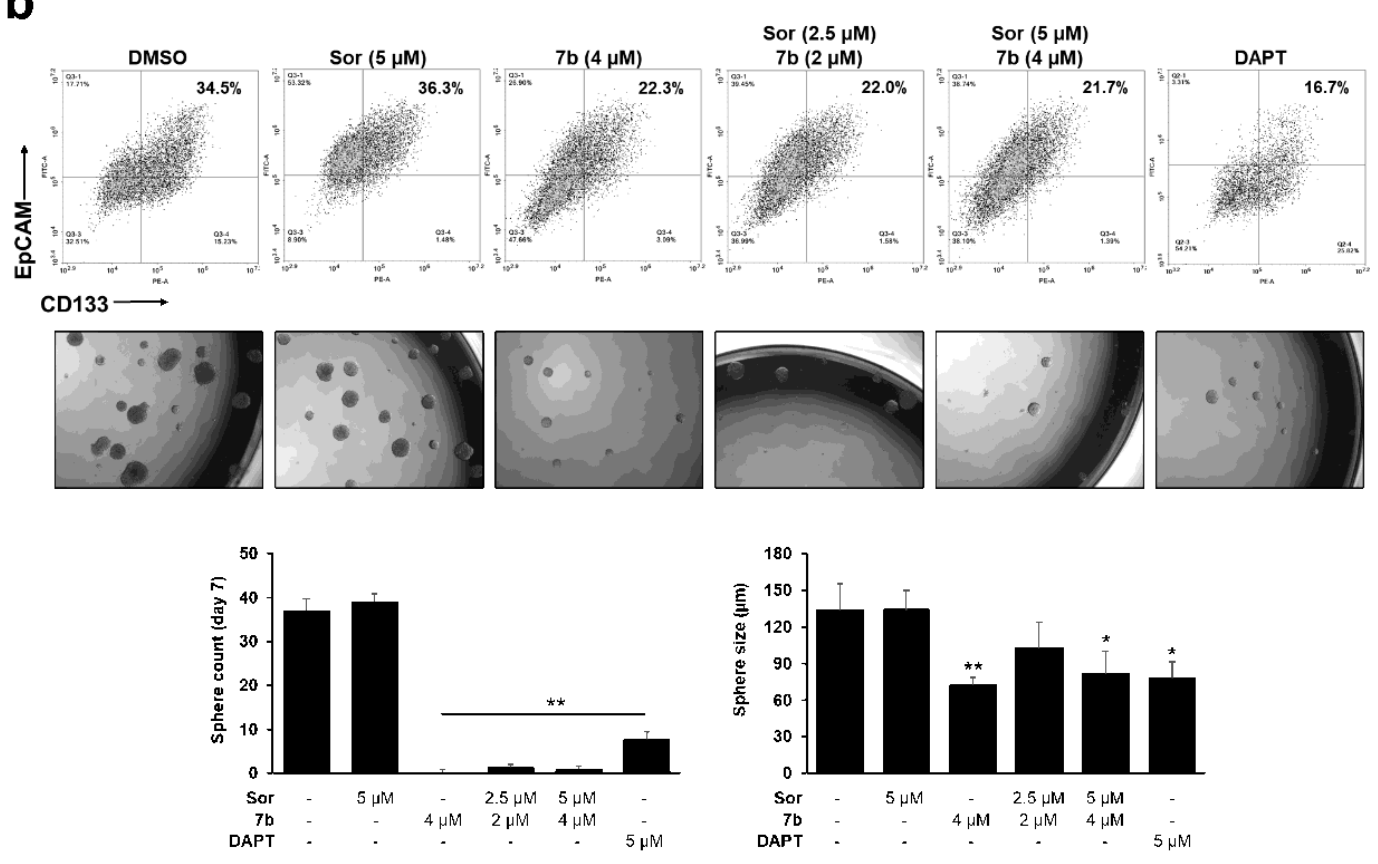

C
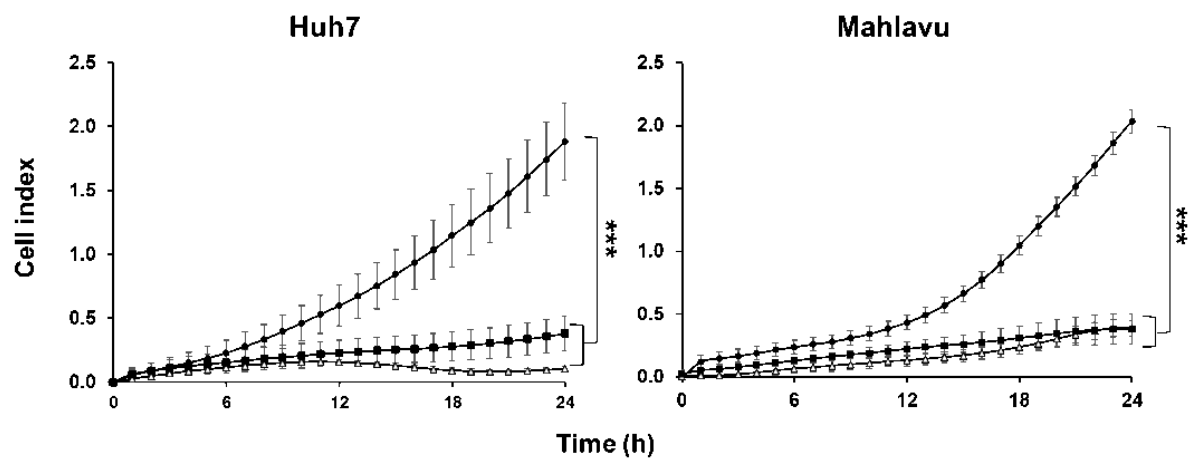

\section{Figure 7}

7b reduces enrichment of LCSCs and the migration capacity of HCC cells. Huh7 and Mahlavu cells were treated with sorafenib $(5 \mu \mathrm{M})$, DAPT $(5 \mu \mathrm{M})$, compound $7 \mathrm{~b}(2 \mu \mathrm{M})$, or DMSO control for $72 \mathrm{~h}$. (a) Images represent flow cytometric analysis of CD133/EpCAM positivity in Huh7 cells, and CD90 positivity in Mahlavu cells upon treatment with indicated compounds/inhibitors. Upper-right quadrant (UR): doublepositive cells for CD133 and EpCAM for Huh7 cells; upper-window: positivity for CD90 for Mahlavu cells. 
(b) Flow cytometric analysis of CD133/EpCAM positivity in Huh7 cells treated with compound 7b or sorafenib alone and with combinations of compound $7 \mathrm{~b}$ and sorafenib and representative images of spheres formed by Huh7 cells. Bar graphs indicate quantitative analysis of sphere count and diameter in different treatment groups. (c) Cell migration index of Huh7 and Mahlavu cells treated with positive control, Taxol $(20 \mathrm{ng} / \mathrm{ml})$ or compound $7 \mathrm{~b}(2 \mu \mathrm{M}$ for Huh7 and $8 \mu \mathrm{M}$ for Mahlavu) for 24 hours.

\section{Supplementary Files}

This is a list of supplementary files associated with this preprint. Click to download.

- KahramanetalSupplementaryinfo.pdf 